\title{
An Improved Power Management System in Electrosurgery Unit Monopolar Design
}

\author{
Riga Domigata ${ }^{1}$, Tri Bowo Indrato ${ }^{1}$, Triana Rahmawati ${ }^{1}$, Narongrit Sanajit ${ }^{2}$ \\ ${ }^{1}$ Electromedical Department of Engineering Poltekkes Kemenkes, Surabaya \\ Jl. Pucang Jajar Timur No. 10, Surabaya, 60245, Indonesia \\ ${ }^{2}$ Mahanakorn University of Technology, Department of Electrical Power Engineering, Nongchok, Bangkok, 10530, Thailand \\ 140 Chueam Samphan Rd, Khwaeng Krathum Rai, Khet Nong Chok, Krung Thep Maha Nakhon 10530, Thailand, Bangkok \\ E-mail: rigadomigata@gmail.com
}

\begin{tabular}{|c|c|}
\hline Article Info & Abstract \\
\hline $\begin{array}{l}\text { History Articles: } \\
\text { Receive Mei 15, } 2020 \\
\text { Revised August 10, } 2020 \\
\text { Received August 30, } 2020\end{array}$ & $\begin{array}{l}\text { In using the Electrosurgery unit, improper power settings and modes can cause tissue damage, so it } \\
\text { is necessary to adjust the cutting mode and power settings needed. The purpose of this research is to } \\
\text { design power control and cutting mode in Electrosurgery using Arduino nano as a regulator of power } \\
\text { and pulse or duty cycle. The contribution of this research is the creation of power control and mode in } \\
\text { the Electrosurgery unit to increase power and cutting mode. This is to control the electrosurgery power. } \\
\text { The LM2907 IC frequency to voltage circuit is used as a voltage regulator, which is issued according to }\end{array}$ \\
\hline $\begin{array}{l}\text { Keywords: } \\
\text { electrosurgery unit } \\
\text { tissue } \\
\text { frequency } \\
\text { power management }\end{array}$ & $\begin{array}{l}\text { the frequency with the power selection LOW, MEDIUM, HIGH. The method used is the CMOS } 4069 \\
\text { device as a frequency generator at } 250 \mathrm{kHz} \text {, then the driver pulse is passed and controlled by the } \\
\text { ATmega328 IC, then forwarded to an inverter circuit that functions to increase the voltage and output } \\
\text { in the form of power. After the measurement process is carried out on the inverter input with a Blend } \\
\text { mode three value, the voltage value is obtained at the low setting } 100 \mathrm{~V} \text { error } 0.03 \% \text {, medium setting } \\
110 \mathrm{~V} \text { error } 0.02 \% \text {, High setting } 120 \mathrm{~V} \text { Error }-0.02 \% \text {. While the measurement results in the coagulation } \\
\text { mode are the low setting error of } 100 \mathrm{~V} 0.05 \% \text {, the medium setting error is } 110 \mathrm{~V} \text { 0.08\%. High setting } \\
\text { error is } 130 \mathrm{~V} 0.003 \% \text {. The measurements show that the error in power management is lower than } 1 \% \text {. } \\
\text { The results of this study can be implemented in the electrosurgery unit to reduce tissue damage due to } \\
\text { a lack of cutting modes and power management. }\end{array}$ \\
\hline
\end{tabular}

\author{
The corresponding author: \\ Tri Bowo Indrato \\ Electromedical Department of Engineering \\ Poltekkes Kemenkes, Surabaya \\ J1. Pucang East Jajar No. 10, Surabaya, 60245, Indonesia \\ E-mail: rigadomigata@gmail.com
}

This job open access articles and licensed under Creative Commons Attribution-Non-Commercial 4.0 License International,

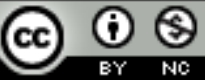

\section{INTRODUCTION}

In the operation and use of Electrosurgery, the various power settings and cutting modes are very important problems. In the use of Electrosurgery in need of an understanding of the human body tissues and the appropriate power and mode to avoid the damaging effects of the body tissues [1] [2].According to the most basic research that makes Electrosurgery dangerous one of them because of lack of understanding of monopolar Electrosurgery Technology, where the current is produced larger and will spread wider throughout the body than by bipolar Therefore, the correct power and mode settings are needed to reduce the risk of accidents [3]. The heat generated by Electrosurgery can also impact the tissues if the tissue implants are very sensitive to heat as the slightest amount of current and voltage over the tissues can damage the cell tissues; therefore power management is necessary [4] [5] [6][7][8]. Understanding how the electrical flow through the body can help the doctor in preventing unexpected medical accidents because each body part has a different resistive [9]. Electric surgical Knives Use the principle of electrical charge in tissue surgery, or an electrode contact with a tissue is not required. With the springboard effect that burns the tissue, the surgical result will be more sterile [10] [11] [12]. Through understanding the output characteristics of Electrosurgery will allow the surgeon more effectively to vary the power output of the appliance so that the power selection settings will not impact or negatively affect the Tissues effect [13].

This ESU tool was once created by Goble with generator frequency, and pulse control[14], but it still does not have power control. Tomson, in the year 2005, improved in Electrosurgery with voltage and frequency regulator [15], the device still has a shortage of the Pulse controller. Daniel Friedrich in 2011 developed the Electrosurgery unit with Output power Regulator to limit current and voltage[16], but because it uses close looping control it slower the speed of the entire control system is often 
orders-of-magnitude slower than the converter AC output, results in substantial deviations of the per-cycle delivered power from the desired value. In 2012 Daniel Friedrich improvement of electrosurgery output with dual current mode control power regulator[17], but it still needs to set current and voltage limits manually, which makes it hard to use. In 2018 Ali Alzaidi made the development of electrosurgery frequency generator[18]. In this tool, no power and mode selection only pulse mode.

Based on the identification results of the problems above, the problems that must be fixed in this study are the lack of cutting modes and the lack of power regulation and selection. Then the author will design electrosurgery unit monopolar (coagulation) with the addition of Blend mode 3 with the power selection displayed to the LCD character and change the system to Arduino with a frequency of $250 \mathrm{kHz}$ In accordance with standard electrosurgery units with a frequency of more than $100 \mathrm{kHz}$ [19] and using an inverter to increase the output power [20] The main parts and materials use ic 4093, transistor, transformer, and MOSFeet [21] [22] [23] [24]. By making an Electrosurgery unit with the addition of modes and power selection, it is hoped that it can avoid unnecessary tissue damage.

This article consists of 5 parts, part II contains methods and methods to be worked on, part III is the results obtained in this study, part IV discusses the findings, and Part V the conclusions.

\section{MATERIALS AND METHODS}

\section{A. Experimental setup}

This study uses a $250 \mathrm{kHz}$ input frequency with a $100 \%$ duty cycle for $6 \%$ cutting mode on $94 \%$ off for coagulation mode, $25 \%$ cutting mode on $75 \%$ off for Blend 3 . The power settings used are low, medium, high. The media used is meat.

\section{1) Materials and Tools}

This research uses IC CMOS (CD4069B, Texas Instrument, America) as a high-frequency generator, MOC (4N35, Agilent Technologies, America), MOSFET (740B, Fairchild Semiconductor, America) driver circuit as a type $A B$ current amplifier, ferrite transformer Type: 42-M58802P01 as voltage booster. Microcontroller (Nano, Arduino, Italy) is used as a microcontroller to regulate PWM output and power selection. IC frequency to voltage(LM2907, Texas Instrument, Amerika) to convert the frequency to voltage. Digital Oscilloscope (Textronic, DPO2012, Taiwan) is used to measure frequency.

\section{2) Trial}

In this study, the entire series was completed and measured the frequency and voltage inputs inverter using an oscilloscope.

\section{B. Block diagram and flowchart}

When the switch is on, then the input voltage from the PLN to the switch to activate the DC power supply, then the whole series will get a voltage from the DC supply. The input comes from a hand switch that functions as a switch to perform surgery with coagulation and blend modes with the buzzer indicator sounding besides using the push button found on the handpiece. Furthermore, the coagulation and blend buttons function as a mode regulator on ESU. The power selection button is used for power management via the microcontroller $r$ as we want, and then it will be displayed on the character LCD for coagulation mode power selection. Furthermore, to set the pulse or duty cycle in coagulate and blend mode, there is a pulse control block that is driven through the microcontroller. The coagulation duty cycle is $6 \%$ on, and the blends duty cycle is $25 \%$ on $75 \%$ off.

Because the surgery process uses a high frequency and has been determined, there is a generator circuit that produces a high frequency, the oscillator. From the oscillator block, then entered the pulse regulator block and will be processed in the driver block that has been done before the power settings. Then after processing through, the driver block will then enter the ferrite transformer circuit. Ferrite transformer in the above series of blocks functions as an increase in the output voltage of the driver. Then the output of the ferrite transformer will enter the passive electrode and can be used for the surgical process (Fig.1).

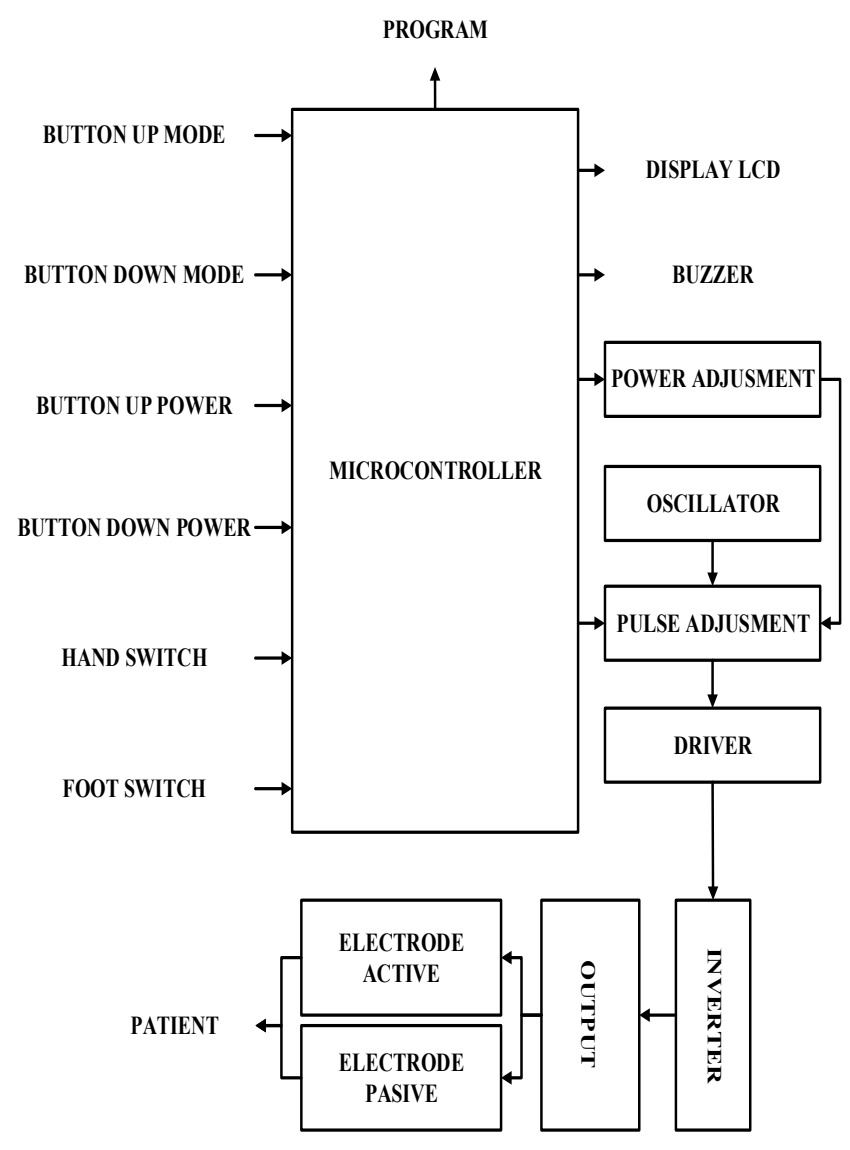

Fig. 1. A block diagram of electrosurgery unit monopolar (coagulation) 


\section{The Flowchart}

The flow chart proposed method in Fig.2. When the switch is on, then the LCD character screen will start initialization. The LCD screen will display the selection of modes and power selection. The buttons are UP and Down, which serves to choose the mode and power settings that can be done freely without having to select the mode first or without having to select the power first. When the footswitch and or hand switch is pressed, then the tool will work with the power appearance on the LCD character screen. FinishedCircuit

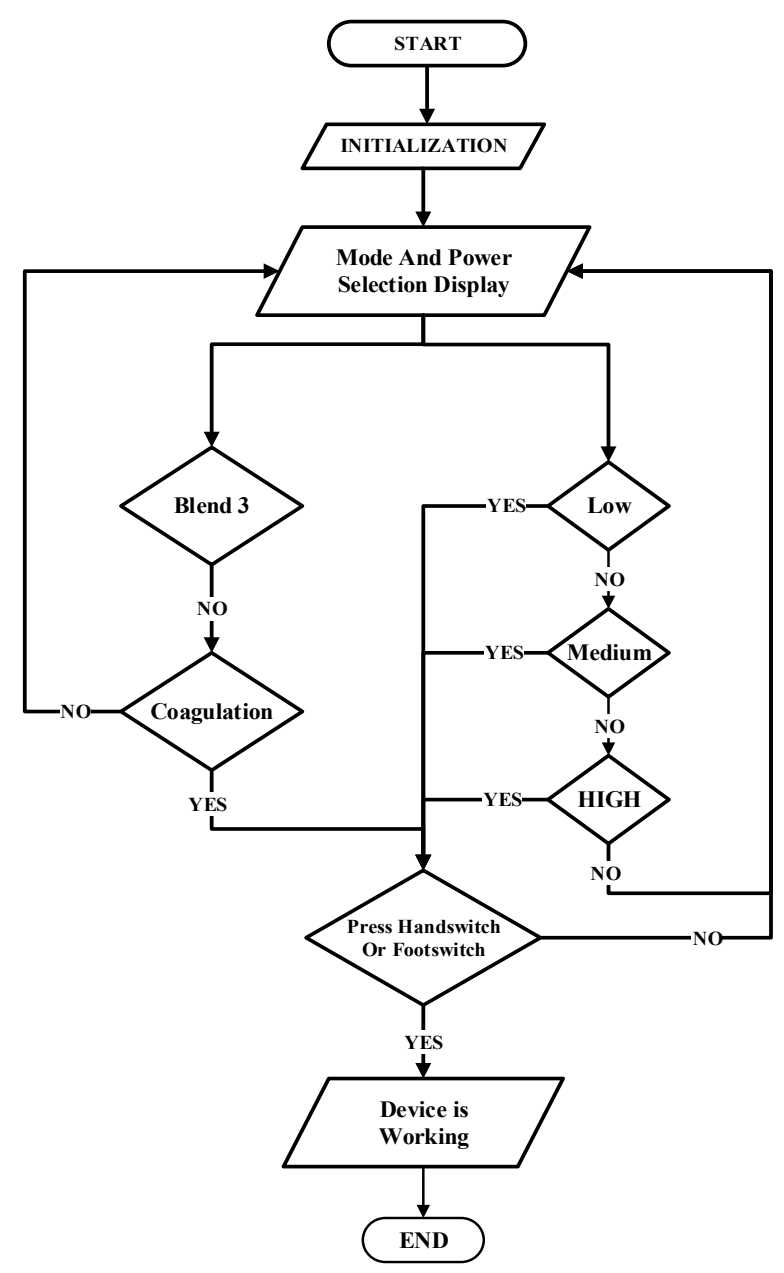

Fig. 2. The Flowchart electrosurgery unit monopolar

\section{1) Oscillator}

In the Fig.3 is the $250 \mathrm{kHz}$ oscillator circuit and main pulse generator that works continuously. With IC CMOS CD 4069 as a high-frequency generator that will be used in this monopolar unit electrosurgery aircraft. The high frequency used in $250 \mathrm{kHz}$. These pulses are square/square pulses. The oscillator circuit with NOT gate is also called Schmitt Trigger. The output is in the form of a rectangular pulse with an output condition that switches from high to low and returns to high, and so on.

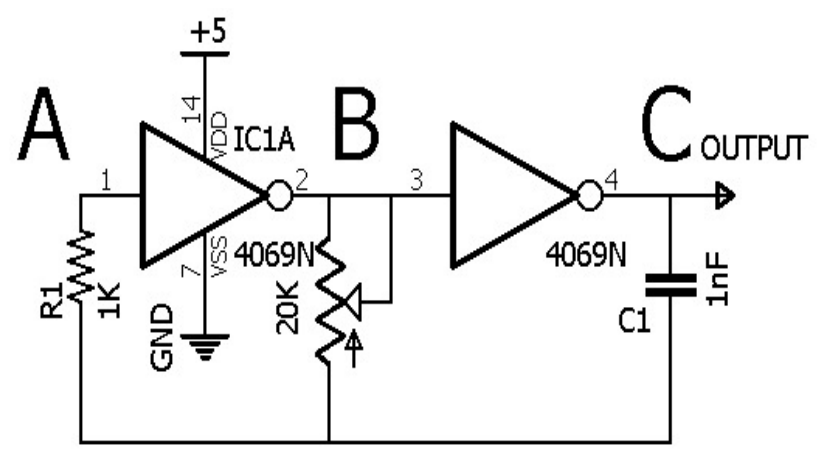

Fig. 3. Oscillator

\section{2) The Pulse Management Circuit}

The pulse regulating circuit in Fig.4 is a circuit that functions to regulate the shape of the main pulse, which was originally continuous to be non-continuous because it is cut by pulses with duty cycle $94 \%$ off $6 \%$ on and $75 \%$ off $25 \%$ on for blend 3 . To adjust the duty cycle used PWM generates by a microcontroller to control ic $4503 \mathrm{~N}$.

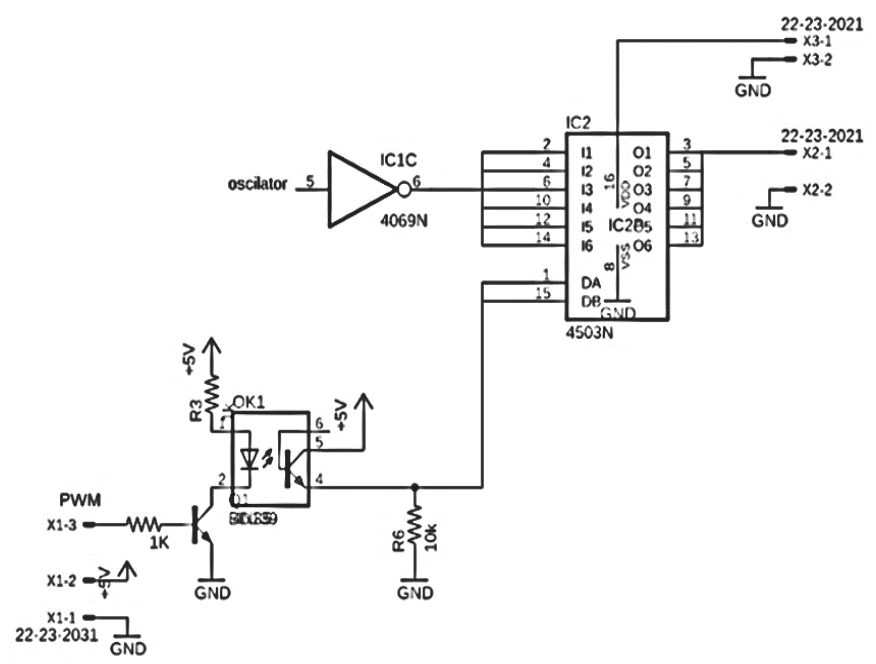

Fig. 4. The Pulse Management Circuit

3) The Pulse Regulator Driver Circuit

The pulse regulator driver circuit in Fig.5 is a circuit that serves to regulate the power duty cycle that has been set by the power Management by following per under the desired pulse settings. In the pulse regulator circuit, the most important part is the IRF540 which functions as an amplifier and driver before entering the final transformer inverter circuit 


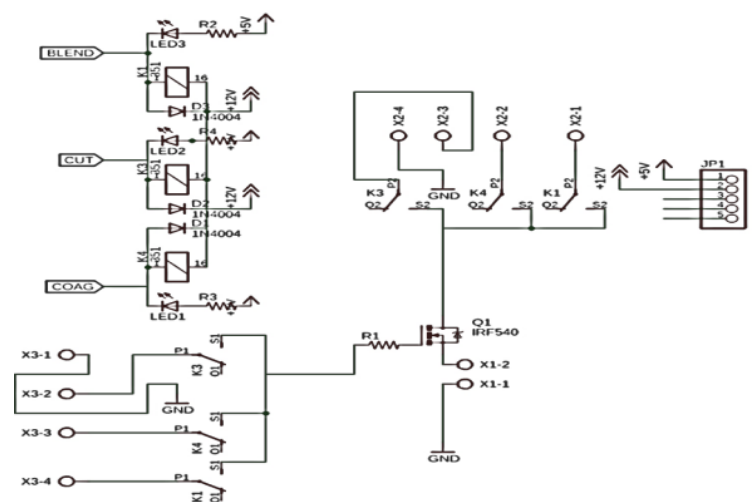

Fig. 5. The Pulse Regulator Driver Circuit

\section{4) Power Management Circuit}

The power Management circuit in Fig.6 is a circuit that functions to regulate the output frequency amplitude of the transformer. With IC LM2907 as a frequency converter to voltage. The frequency is controlled through a microcontroller circuit

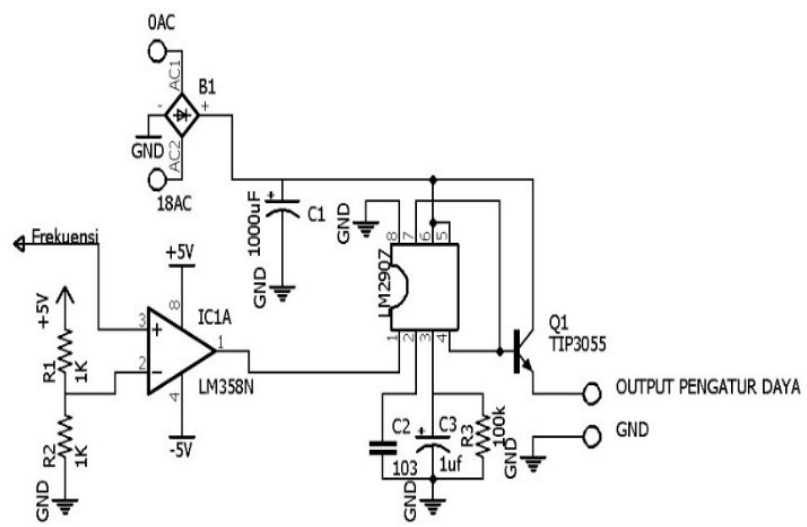

Fig. 6. Power Management Circuit

\section{5) Inverter Circuit}

An inverter circuit in Fig.7 is a circuit used to convert a 94 Volt DC voltage into a high voltage A. in the circuit, there is the IRF740 MOSFET, which is used for high voltage drivers.

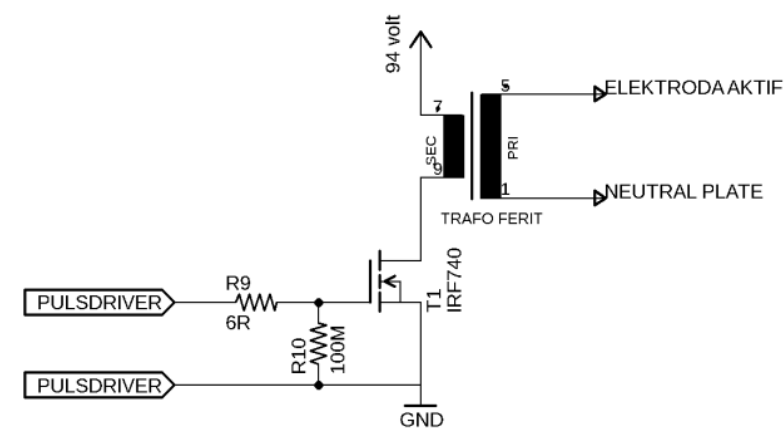

Fig. 7. Power Inverter Circuit

\section{RESULT}

In this study, the electrosurgery unit was tested on the unit's electrosurgery analyzer. The error value was below $5 \%$.

\section{1) Electrosurgery Design}

Images from the inside and outside of electrosurgery units can be seen in Fig. 8 and Fig. 9. The microcontroller board consists of a microcontroller circuit, pulse regulating circuit, power regulator, oscillator, and handpiece control. In Fig.9, ESU is equipped with a handpiece and footswitch as a cutting and coagulation control, as well as a ground plate as a passive electrode.

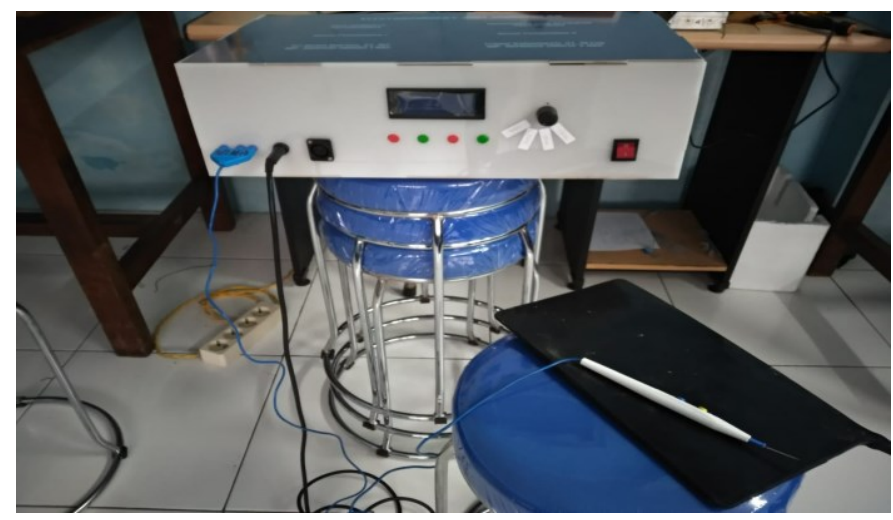

Fig. 8. Electrosurgery Unit

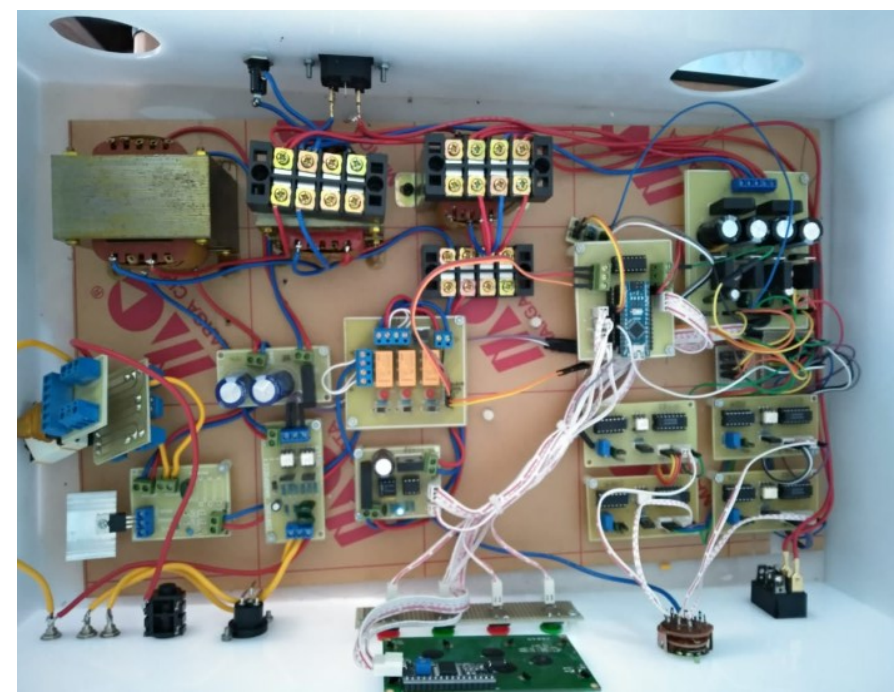

Fig. 9. Circuit Design

2) The results of the output Frequency measurement using Oscilloscope

Measurements are made on the oscillator output, which is influenced by the value of resistance on multiturn and capacitor. Measurement using an oscilloscope in TABLE I. with error $0.0016 \%$ and the Grafik deviation Fig.10 is 1.14.and the square wave output of the oscillator can be seen in the image in Fig.11 
TABLE I.

MEASUREMENT TABLE OF 250KHZ OSCILLATOR OUTPUT

\begin{tabular}{cc}
\hline \multicolumn{2}{c}{ Oscillator circuit } \\
\hline Measurement & Oscilloscope Display $(\mathbf{K h z})$ \\
\hline 1. & 250 \\
\hline 2. & 249 \\
\hline 3. & 252 \\
\hline 4. & 251 \\
\hline 5. & 250 \\
\hline Mean & $\mathbf{2 5 0 . 4}$ \\
\hline
\end{tabular}

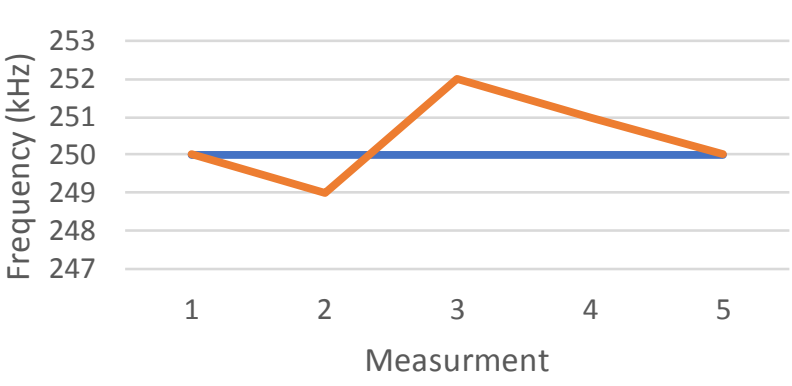

$\longrightarrow$ Setting Reading

Fig. 10. Frequency output measurement

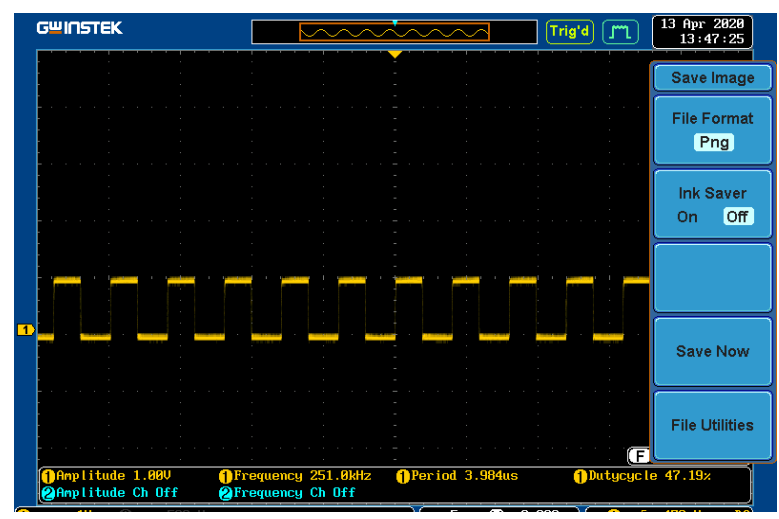

Fig. 11. Frequency output measurement Oscilloscope

\section{3) measurement error}

TABLE II. ELECTROSURGERY MODE BLEND 3 MEASUREMENT ERROR FOR THE DESIGN.

\begin{tabular}{ccr}
\hline \multicolumn{3}{c}{ INPUT INVERTER } \\
\hline POWER & Voltage & Error (\%) \\
\hline LOW & $102 \mathrm{~V}$ & 0.03 \\
\hline MEDIUM & $112 \mathrm{~V}$ & 0.02 \\
\hline HIGH & $117 \mathrm{~V}$ & -0.02 \\
\hline
\end{tabular}

TABLE III.

ELECTROSURGERY

MODE

CoAgulation MEASUREMENT ERROR FOR THE DESIGN.

\begin{tabular}{ccc}
\hline \multicolumn{3}{c}{ INPUT INVERTER } \\
\hline POWER & Voltage & Error (\%) \\
\hline LOW & $104.8 \mathrm{~V}$ & 0.05 \\
\hline MEDIUM & $108.6 \mathrm{~V}$ & 0.08 \\
\hline HIGH & $130.4 \mathrm{~V}$ & 0.00 \\
\hline
\end{tabular}

The voltage that is read through Oscilloscope in TABLE II Blend 3 and TABLE III Coagulation, reading low mode, with setting $100 \mathrm{~V}$, has an error $0.03 \%$ and $0.05 \%$. Then in the medium power mode, setting $110 \mathrm{~V}$ have an error $0.02 \%$ and $0.08 \%$. And in the high power mode with setting $120 \mathrm{~V}$ for Blend 3 have an error $-0.02 \%$ and setting $130 \mathrm{~V}$ for coagulation has an error $0.00 \%$.

\section{DISCUSSION}

Overall this research electrosurgery unit Blend 3 and coagulation mode with more easy usage power and mode selector with an error of less than $1 \%$ in every power selection in TABLE II and TABLE III with only use simple circuit of frequency to voltage and pulse management circuit to control power and pulse duty cycle of all cutting mode. I was using a frequency generator with an output of $250 \mathrm{kHz}$ with an error of less than $1 \%$ and with deviation 1.14 .

Daniel Friedrich [17], in 2011 and 2012, propose a similar study with improvement power but not the pulse control for cutting mode and more complex usage. The improvement of these studies is in the cutting modes, power management, and simple usage. The cutting mode is controlled in a pulse management circuit with the Duty cycle input from Arduino that can be fixed set to $0-100 \%$ duty cycle, a corresponded mode used in the Electrosurgery. The power selection use frequency to voltage also can be fixed set with control of frequency input from Arduino to increase voltage and current in Electrosurgery. In the practical system, it can be implemented in Electrosurgery Unit to reduce Tissue damage due to a lack of cutting mode and power management. Despite the improvement in cutting mode and power management, the power management Still not using the power settings in the form of appropriate numbers.

\section{CONCLUSION}

The purpose of this study is to make an electrosurgery unit with power management and increase cutting mode selection to decrease tissue damage because of a lack of power management and cutting mode. This research has found that power management can be used in the electrosurgery unit to limit the power that is used for cutting with an error of less than $1 \%$ with a simple setting and usage. In summary, the study unveiled the oscillator circuit can issue a frequency and the inverter circuit can increase the desired voltage to perform surgery and can be controlled using footswitch and hand switch with the selection of low, medium, and high modes that controlled with power 
management circuit. Pulse management can control the duty cycle of Electrosurgery depended on the mode uses. Further experimental can make the system with more cutting mode and power management with appropriate watt.

\section{REFERENCE}

[1] N. Aggarwal, K. Ahuja, N. Pal, R. Pannu, and V. Berwal, 'Electrosurgery: Welcome Part of Modern Surgery A R T I C L E I N F O', J. Appl. Dent. Med. Sci. NLM ID, vol. 3, no. 3037, pp. 2454-2288, 2017.

[2] S. T. Vedbhushan, M. A. Mulla, Haroonrasid, and D. M. Chandrashekhar, 'Surgical Incision by High-Frequency Cautery', Indian J. Surg., vol. 75, no. 6, pp. 440-443, Dec. 2013, DOI: 10.1007/s12262-012-0520-x.

[3] P. M. McQuail, B. S. McCartney, J. F. Baker, and P. Kenny, 'Diathermy awareness among surgeons-An analysis in Ireland', Ann. Med. Surg., vol. 12, pp. 54-59, 2016, DOI: 10.1016/j.amsu.2016.10.006.

[4] F. J. Pettersen, T. Martinsen, J. O. Høgetveit, and Ø. G. Martinsen, 'Unintentional heating at implants when using electrosurgery', Proc. Annu. Int. Conf. IEEE Eng. Med. Biol. Soc. EMBS, vol. 2015-Novem, pp. 5805-5808, 2015, DOI: 10.1109/EMBC.2015.7319711.

[5] P. Samatha Yalamanchili, P. Davanapelly, and H. Surapaneni, 'Electrosurgical applications in Dentistry', Sch. J. Appl. Med. Sci. Sch. J. App. Med. Sci, vol. 1, no. 5, pp. 530-534, 2013.

[6] J. L. Tokar et al., 'Electrosurgical generators', Gastrointest. Endosc., vol. 78, no. 2, pp. 197-208, 2013, DOI: 10.1016/j.gie.2013.04.164.

[7] V. Sydorets, A. Dubko, O. Bondarenko, and R. Kosenko, 'Influence of skin effect on current flow through electrodes of electro-surgical instruments and biological tissue', Proc. Bienn. Balt. Electron. Conf. $B E C$, vol. 2016-Novem, pp. 211-214, 2016, DOI: 10.1109/BEC.2016.7743766.

[8] R. E. Dodde, J. S. Gee, J. D. Geiger, and A. J. Shih, 'Monopolar electrosurgical thermal management for minimizing tissue damage', IEEE Trans. Biomed. Eng., vol. 59, no. 1, pp. 167-173, 2012, DOI: 10.1109/TBME.2011.2168956.

[9] R. M. Fish and L. A. Geddes, 'Conduction of electrical current to and through the human body: a review.', Eplasty, vol. 9, p. e44, Oct. 2009, ISSN: 19907637.

[10] J. Sunardi et al., 'Rancang Bangun Pisau Bedah Listrik Dengan Frekuensi $450 \mathrm{Khz}$ ( Esu )', no. November, pp. 600-604, 2011, ISSN 1978-0176.

[11] A. K. Ward, C. M. Ladtkow, and G. J. Collins, 'Material removal mechanisms in monopolar electrosurgery', Annu. Int. Conf. IEEE Eng. Med. Biol. - Proc., pp. 1180-1183, 2007, DOI: 10.1109/IEMBS.2007.4352507.

[12] D. L. Carr-Locke and J. Day, 'Principles of Electrosurgery', Success. Train. Gastrointest. Endosc., pp. 125-134, 2011, DOI: 10.1002/9781444397772.ch11.

[13] M. G. Munro, The SAGES Manual on the Fundamental Use of Surgical Energy (FUSE). 2012.

[14] [C. C. . Goble, 'Electrosurgical Generator and System', Patent :US006093186, 2000.

[15] R. Tompson, 'Electrosurgical Generator And Method with Voltage and Frequency Regulated High-Voltage Current Mode Power Supply', Paten:US006939347B2, 2005.

[16] D. A. Friedrichs, R. W. Erickson, and J. Gilbert, 'A new system architecture improves output power regulation in electrosurgical generators', Proc. Annu. Int. Conf. IEEE Eng. Med. Biol. Soc. EMBS, pp. 6870-6873, 2011, DOI: 10.1109/IEMBS.2011.6091694.

[17] D. A. Friedrichs, R. W. Erickson, and J. Gilbert, 'A new dual currentmode controller improves power regulation in electrosurgical generators', IEEE Trans. Biomed. Circuits Syst., vol. 6, no. 1, pp. 39-44, 2012, DOI: 10.1109/TBCAS.2011.2159859.

[18] A. I. Alzaidi, A. Yahya, T. T. Swee, and N. Idris, 'Development of highfrequency generator for bipolar electrosurgical unit', Int. J. Eng. Technol., vol. 7, no. 2, pp. 20-23, 2018, DOI: 10.14419/ijet.v7i2.29.13118.
[19] T. J. C. Faes, H. A. van der Meij, J. C. de Munck, and R. M. Heethaar, 'The electric resistivity of human tissues $(100 \mathrm{~Hz}-10 \mathrm{MHz})$ : a metaanalysis of review studies', Physiol. Meas., vol. 20, no. 4, pp. R1-R10, Nov. 1999, DOI: $10.1088 / 0967-3334 / 20 / 4 / 201$.

[20] N. Sanajit and W. Meesrisuk, 'A High-Frequency PWM Half-Bridge Inverter for Electrosurgical Cutting Applications', ICEMS 2018 - 2018 21st Int. Conf. Electr. Mach. Syst., pp. 827-830, 2018, DOI: 10.23919/ICEMS.2018.8549089.

[21] C. K. Ng, 'Clarifying concepts and gaining a deeper understanding of ideal transformers', Eur. J. Phys., vol. 39, no. 3, 2018, DOI: 10.1088/1361-6404/aaabc4.

[22] A. Dorian, I. Florin, and M. F. Predus, 'The testing stand of the ferrite core transformers', 2017 10th Int. Symp. Adv. Top. Electr. Eng. ATEE 2017, no. 1, pp. 76-81, 2017, DOI: 10.1109/ATEE.2017.7905061.

[23] T. Tang and C. Burkhart, 'Hybrid MOSFET/driver for ultra-fast switching', IEEE Trans. Dielectr. Electr. Insul., vol. 16, no. 4, pp. 967970, Aug. 2009, DOI: 10.1109/TDEI.2009.5211841.

[24] K. Rauff, A. Rilwan, U. Farouk, and D. Joshua, 'Construction of a Simple Transformer to Illustrate Faraday's Law of Electromagnetic Induction along Side Mutual Inductance', Phys. Sci. Int. J., vol. 12, no. 1, pp. 1-5, 2016, DOI: $10.9734 / \mathrm{psij} / 2016 / 28280$. 